\title{
(6) OPEN ACCESS \\ Confounding factors and genetic polymorphism in the evaluation of individual steroid profiling
}

\author{
Tiia Kuuranne, ${ }^{1}$ Martial Saugy, ${ }^{2}$ Norbert Baume ${ }^{2}$
}

'Doping Control Laboratory, United Medix Laboratories Ltd., Helsinki, Finland

${ }^{2}$ Swiss Laboratory for Doping Analyses, University Center of Legal Medicine, Geneva and Lausanne, Epalinges, Switzerland

\section{Correspondence to} Dr Norbert Baume, Swiss Laboratory for Doping Analyses, University Center of Legal Medicine, Geneva and Lausanne, Chemin des Croisettes 22, Epalinges 1066, Switzerland; norbert.baume@chuv.ch

Accepted 4 March 2014
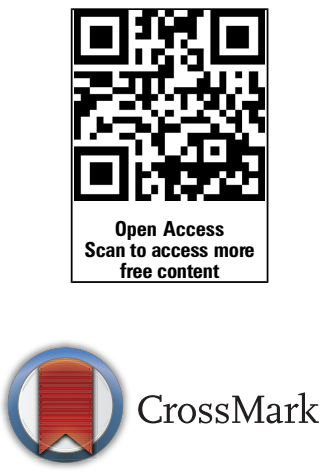

To cite: Kuuranne $T$ Saugy M, Baume N. Br J Sports Med 2014;48: 848-855.

\section{ABSTRACT}

In the fight against doping, steroid profiling is a powerful tool to detect drug misuse with endogenous anabolic androgenic steroids. To establish sensitive and reliable models, the factors influencing profiling should be recognised. We performed an extensive literature review of the multiple factors that could influence the quantitative levels and ratios of endogenous steroids in urine matrix. For a comprehensive and scientific evaluation of the urinary steroid profile, it is necessary to define the target analytes as well as testosterone metabolism. The two main confounding factors, that is, endogenous and exogenous factors, are detailed to show the complex process of quantifying the steroid profile within WADA-accredited laboratories. Technical aspects are also discussed as they could have a significant impact on the steroid profile, and thus the steroid module of the athlete biological passport (ABP). The different factors impacting the major components of the steroid profile must be understood to ensure scientifically sound interpretation through the Bayesian model of the ABP. Not only should the statistical data be considered but also the experts in the field must be consulted for successful implementation of the steroidal module.

\section{INTRODUCTION}

Since the advent of the fight against doping in sports in the 1970s, detection of the prohibited substances has seen many improvements. Targeted analyses using technologies such as gas chromatography coupled to mass spectrometry (GC-MS) have been the golden standard for many years. ${ }^{1-4}$ Liquid chromatography coupled to MS (LC-MS) allowed for much easier and straightforward sample preparation and shortened the turnaround time to complete the analyses. ${ }^{5}$ Constant development in the MS instrumentation has enabled a continuous increase of performance in terms of sensitivity as well as specificity. ${ }^{6}$

Whereas exogenous substances can be identified by qualitative analysis of appropriate target compounds, the situation is more complex in case of endogenous performance-enhancing substances, such as testosterone $(\mathrm{T})$, which are not only available as pharmaceutical products, but are also produced by human body. ${ }^{7}$ In these situations, the World Anti-Doping Agency (WADA)-accredited laboratories should be capable of distinguishing between the doping use and clinical/pathological conditions to protect the integrity of clean sport by efficient control, and also to guarantee the fair processes of each individual athlete.

Anabolic steroids are mainly excreted through the urinary route, requiring modifications of their hydrophobic chemical structures. Phase I and phase
II metabolic reactions are responsible for, respectively, functionalisation and addition of conjugates (ie, glucuronides or sulfates) ${ }^{8-11}$ to steroids, thereby increasing their hydrophilicity and allowing their dissolution and elimination in urine mixture. Since steroid conjugates analysis is not compatible with GC-MS, the only analytical technique recognised by WADA for endogenous steroids quantification in urine, ${ }^{12}$ deconjugation of the conjugated moiety by enzymatic hydrolysis ( $\beta$-glucuronidase) is a crucial step during sample preparation and prior to GC-MS measurement. ${ }^{13} 14$

Steroid profile consists of the quantification of several glucuroconjugated and free urinary compounds linked to $\mathrm{T}$ and its metabolism (figure 1), and is well known as a potent tool to uncover doping with endogenous anabolic steroids. ${ }^{13}$ 15-18 However, due to a wide interindividual variability in absolute endogenous steroid concentrations originating from various factors, it has been proven that population-based reference values, which were considered for years by every protagonist in the fight against doping, are not always sensitive enough to reveal the potential misuse of anabolic androgenic steroids at an individual level. ${ }^{19}$ For these reasons, there is an obvious need of individual monitoring of the steroid profile to allow a fair evaluation.

The in-competition and out-of-competition testing programmes are the best strategies to screen and confirm adverse analytical findings of exogenous and endogenous steroids. From the basis of these routine analyses, the WADA-accredited laboratories provide harmonised and robust analytical data for steroid profile. Recently, a new technical document TD2014EAAS ${ }^{12}$ has been edited to ensure this harmonisation and is in force from January 2014. A detailed description of selected aspects of TD2014EAAS is given later in this review. The application of these rules should enable a suitable application of steroid module of the athlete biological passport (ABP) and the assessment of steroid profile using the adaptive model

Before the steroidal module, ABP has been developed using a Bayesian approach to deter blood doping based on haematological data obtained in whole blood sample. ${ }^{20} 21$ The haematological module of the ABP has been implemented in 2008 by certain international sport federations and since then this indirect methodology has resulted in sanctioning of numerous athletes for anti-doping rule violation. This achievement stimulated the expansion of the ABP to establish the intraindividual reference ranges to monitor the steroid profile of an athlete ${ }^{22}$ (figure 2). Historically, anti-doping laboratories and sport authorities detect misuse of endogenous steroids based on the ratio between $\mathrm{T}$ and its $17 \alpha$-epimer, 


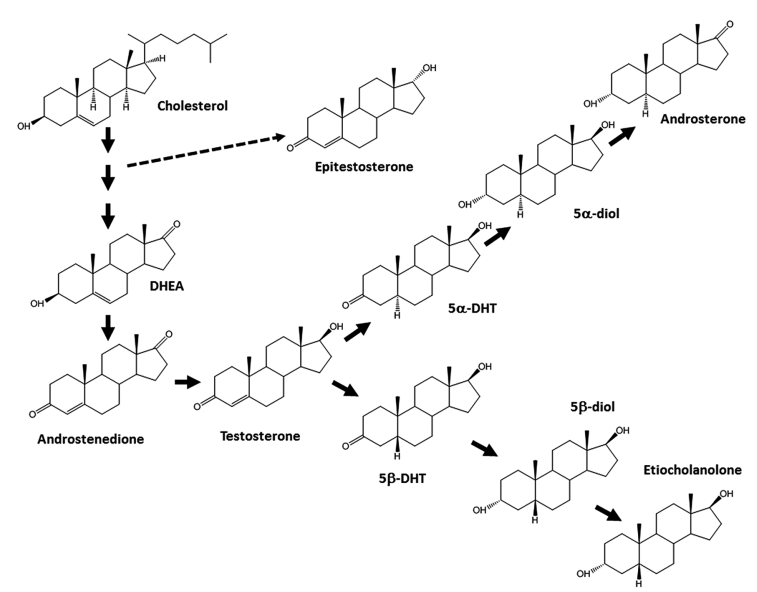

Figure 1 Target analytes of the steroid profile, their interindependence and metabolic pathway. $5 \alpha-/ 5 \beta$-diol, $5 \alpha /$ $5 \beta$-androstane- $3 \alpha, 17 \beta$-diol; DHEA, dehydroepiandrosterone; DHT, dihydrotestosterone.

epitestosterone (E; T/E ratio). ${ }^{16} \mathrm{~A}$ threshold based on previous antidoping data and population studies was first set at 6 by the I O C in $1983^{23-26}$ and later lowered to $4^{27}$ to discriminate between normal and abnormal values. Urine samples showing a T/E ratio above the threshold were then submitted to further analyses such as gas chromatography-combustion-isotope ratio mass spectrometry to evaluate the steroid profile and the endogenous or exogenous origin of the target compounds. ${ }^{28}$ The sensitivity of the T/E ratio approach based on population-based reference ranges has been questioned since $1994 .^{25}$ At that time, individual reference ranges, instead of population-based references, have already been proposed and used in steroid profiling. By the work of Sottas et al, a new and very effective mathematical tool came into this field which allowed an optimised evaluation of the longitudinal data. This mathematical model is, currently, one of the basic tools of the ABP. ${ }^{19}$

The aim of this paper is to summarise and discuss the main factors influencing the analytical processes, steroid profiling and interpretation of the obtained data that will be interpreted through the ABP steroidal module.

\section{ABP AND THE STEROIDAL MODULE}

In 2008, the ABP has been implemented for haematological parameters based on a Bayesian statistical model that allows monitoring of intraindividual fluctuations of blood doping markers. ${ }^{29}$ Knowing that every athlete has his/her own metabolism and responds differently after any drug misuse, this profiling approach is relevant for the results management in the fight against doping. Even if the follow-up of secondary markers indicating a drug intake or a manipulation to increase the performance skills is becoming essential, direct detection of prohibited substances is still necessary to prevent athlete from cheating, and the biological passport profile may assist in targeting the doping control analysis to particular additional tests, such as GC-C-IRMS.

As the urinary steroid profile, especially the $\mathrm{T} / \mathrm{E}$ ratio, is well known as being a stable marker within an individual, ${ }^{12} 24$ the integration of the adaptive steroidal module was a natural evolution of the $\mathrm{ABP}^{30}$ This module aims to identify endogenous anabolic androgenic steroids when administered exogenously and other anabolic agents, such as selective androgen receptor modulators categorised under section S1 of the Prohibited List. ${ }^{31}$ Six markers are considered within the steroidal module which are T, $\mathrm{E}$, androsterone, etiocholanolone, $5 \alpha$-androstane- $3 \alpha, 17 \beta$-diol ( $5 \alpha$-diol) and $5 \beta$-androstane- $3 \alpha, 17 \beta$-diol (5 $\beta$-diol), although Van Renterghem et $a l^{32}$ proposed additional compounds to be integrated in the ABP.

As described in the recently published ABP Operating Guidelines and Compilation of Required Elements, data collection and administration requires specific partners such as anti-doping organisations (ADOs), Athlete Passport Management Unit (APMU), WADA-accredited laboratories, expert panel and WADA. ${ }^{33}$ Each of these entities has its own responsibilities to guarantee reliability and credibility of the ABP programme.

Briefly, ADOs are in charge to perform an appropriate and intelligent follow-up of their athletes according to the International Standard for Testing (IST). ${ }^{34}$ In the process they should also consider the recommendations of the APMUs which are responsible of the passports real-time management through the evaluation of the data of a single sample with respect to the profile generated by the adaptive model in Anti-Doping Administration \& Management System (ADAMS). In addition, APMUs make connections with the expert panels that are necessary to bring out any pathology or confounding factors that could impact analytical results provided by the laboratories which shall adhere to the WADA technical documents TD2014BAR and TD2014EAAS for haematological and steroidal module, respectively. Moreover, expert scientists may also request additional testing for a specific athlete to collect further indications of pathologies or to strengthen an atypical passport finding (ATPF).

Altogether, close cooperation between testing authorities, sample collection authorities and laboratories is mandatory to
Figure 2 Example of steroid profile generated by the Bayesian model of the ABP for the T/E ratio parameter. The blue line represents the measured $T / E$ values, whereas the individual limits are shown by the red lines. $A B P$, athlete biological passport; $E$, epitestosterone; T, testosterone.

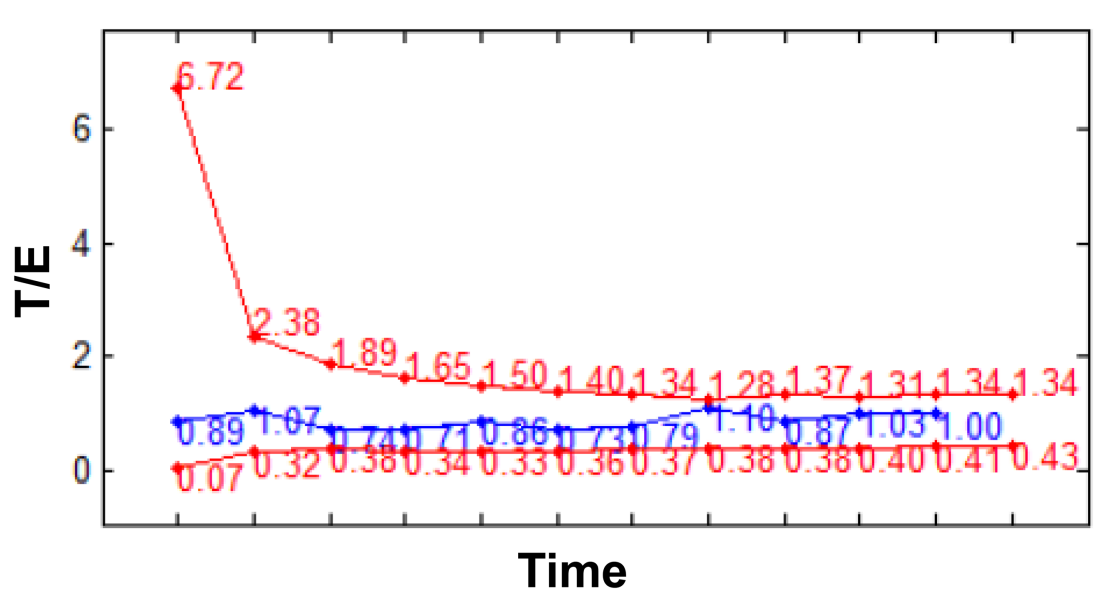


ensure a prompt transfer of information and adequate timing of testing and to allow the ABP programme to be efficient. ${ }^{22}$

\section{Confounding factors for the steroid profile evaluation}

Various factors are capable of influencing either the quantification of the urinary steroid profile or its interpretation. ${ }^{35} 36$ The endogenous or exogenous origin of those issues allows for their classification into two main categories, as shown in figure 3 . Technical aspects related to the specific application of the antidoping regulations or to the steroid analytical measurements in urine are also depicted in figure 3, and will be discussed further in this review.

\section{Endogenous factors}

\section{General considerations}

The ABP aims at monitoring of an individual athlete with respect to his/her own, long-term steroid profile. Interesting parameters with this respect are the general endogenous factors which, on one hand, set the baseline of an individual, and, on the other hand, may lead to 'natural' variation of the profile within a long period of time. Among these factors are, for example, age and gender of the athlete. A major role is played also by ethnicity, but as these interindividual differences are linked essentially to genetic polymorphism, these properties are discussed in connection to androgen metabolism. As a general remark for the interpretation of the results originating before year 2005, it should be notified that the critical value of $\mathrm{T} / \mathrm{E}$ for doping control purposes was $>6$, instead of $>4$.

\section{Ageing and endogenous steroid synthesis}

Raynaud et $\mathrm{al}^{37}$ carried out a study of 141 normal male participants (aged 8-26 years), categorised the population into five groups based on the development stages according to Tanner's scale and compared the excretion profiles of $T$ and $E$ between different age groups. According to their report, excretion of both markers increased significantly during development and correlated highly $(\mathrm{p}<0.001)$ with age. However, a significant difference was observed between the increase of $\mathrm{T}$ and $\mathrm{E}$ relative to age, $\mathrm{T}$ excretion increasing much faster than $\mathrm{E}$ and indicating the potential instability of T/E during puberty. In another study, originating from approximately same time, Dehennin $e t a l^{38}$ studied a population of 140 male participants (aged 13-20 years) with respect to urinary excretion of several endogenous steroids and luteinising hormone $(\mathrm{LH})$. Although they concluded that the increase in excretion rates of glucuronide-conjugated $\mathrm{T}$ and $\mathrm{E}$ correlated with pubertal development, the result was somewhat contrary to earlier one with respect to $\mathrm{T} / \mathrm{E}$, where the observed differences were not significant. In this study, ratio of T-glucuronide to LH, which has been proposed as additional information on T misuse, ${ }^{39}{ }^{40}$ increased throughout puberty. An independent study from Schweizer et $a l^{41}$ with 100 male participants (aged 10-17) supports the results of Dehennin et al, as their study showed insignificant change in $\mathrm{T} / \mathrm{E}$ between different stages, although higher instability of the ratio was associated to prepubertal stages. In a group of adolescent girls (aged 6-17, $\mathrm{n}=256$ ), the same research group observed a decreasing $\mathrm{T} / \mathrm{E}$ ratio during development, most obviously due to larger relative increase in E excretion. The results were similar between exercising and control group of participants. ${ }^{42}$

\section{Gender effects, circadian variations and physical activity}

Interindividual variation in genetics, in enzyme distribution and, consequently, in drug metabolism are discussed later in this review in detail. Briefly, two main families of enzymes contributing the drug metabolism in humans are cytochrome P450 (CYP450), which is responsible for phase I reactions, and uridine diphosphate glucuronosyltransferase (UGT) enzymes, which catalyse the phase II conjugation reaction with glucuronic acid. Gender-dependent differences in enzyme activity have been demonstrated for several CYP isoenzymes and for UGTs, supporting the possibility of quantitative differences between female and male athletes. However, the genes for CYP and UGT proteins are not linked to X-chromosome, and, thus, the prevalence of poor metabolisers should not be expected to be different between genders. ${ }^{43}$

In fact, reference concentration ranges of urinary $\mathrm{T}$ and excreted metabolites have been published previously with lower levels in female participants than in male participants. ${ }^{17} 3944$

Periodical variations in hormones concentrations are well established in different species and matrices. ${ }^{45}$ In humans, $\mathrm{T}$ is also subjected to these fluctuations, as is previously shown in serum, ${ }^{46}$ saliva ${ }^{47}$ and urine. ${ }^{48} 49$ This daily, monthly and even yearly based variability of steroid hormones concentrations should not significantly impact the longitudinal follow-up of
Figure 3 Schematic representation of the variables influencing the steroid profile in the fight against doping. $A B P$, athlete biological passport; GC-C-IRMS, gas chromatography and combustion coupled to isotope ratio mass spectrometry; ITP, initial testing procedure.

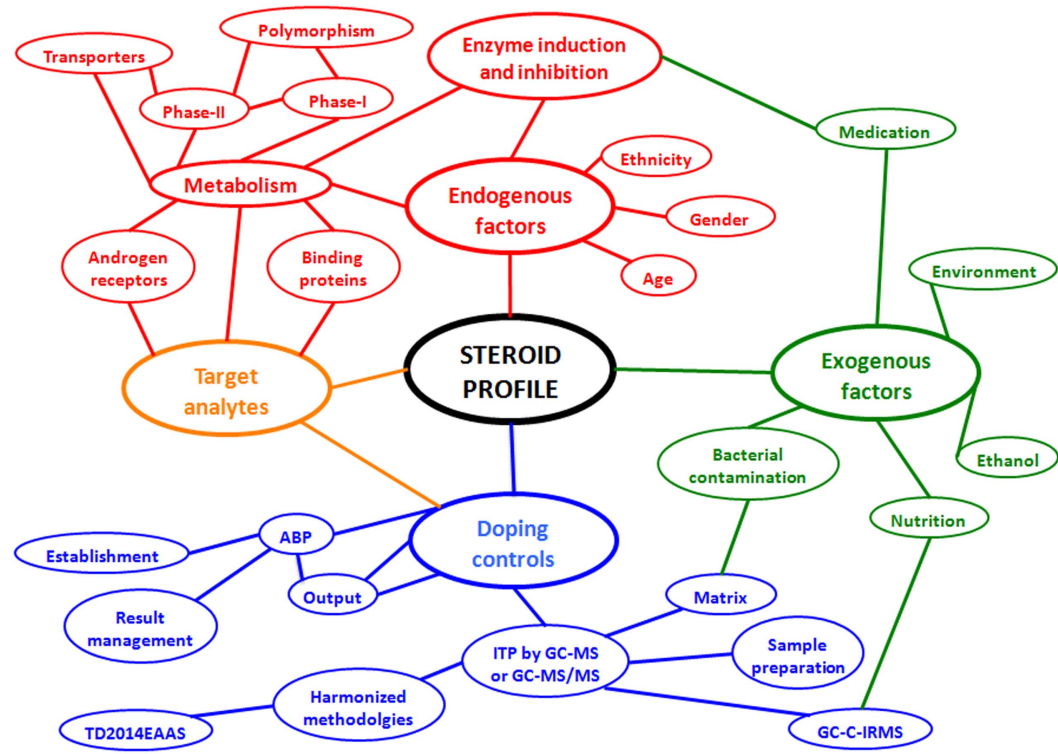


participants, and is included within the normal intraindividual variation of the steroid profile components.

Regarding the urinary steroid profile and physical exercise there are studies concluding differences between sedentary and exercising individuals, ${ }^{50}$ and that the physical activity may influence the elimination of androgens due to changes in sex hormone binding globulin (SHBG) ${ }^{51}$ A group of trained female athletes was investigated by Bricout $e t$ al with respect to urinary steroid profiles during menstrual cycle and compared with nonathlete (sedentary) group. $\mathrm{T}$ and $\mathrm{E}$ were measured from glucuronide-conjugated fraction by radioimmunoassay (RIA), and based on this study, the T/E remained stable between the follicular phase and luteal phase of menstrual cycle within athlete $(0.66 \pm 0.05$ vs $0.69 \pm 0.33)$ and non-athlete $(0.72 \pm 0.26$ vs $0.67 \pm 0.31$ ) groups. As a conclusion, it was stated that although physical training may have an effect on androgen metabolism, active sportswomen can be considered as members of normal population as long as there are no signs of secondary amenorrhoea induced by physical activity. ${ }^{8}$ Regarding male participants, similar results were previously published by Donike et $a l,{ }^{25}$ who showed that high workload during the Tour de France does not influence the T/E ratio in top-level athletes.

During pregnancy, however, female athletes encounter much more dramatic changes. Controlled longitudinal studies of steroid profile during pregnancy are scarce, but according to available data, significant alterations occur not only in the production of progesterone and oestriol, but also in androgen concentrations. For the status of the steroid profile and its interpretation, the most significant factors are pregnandiol (PD) and $\mathrm{T}$ itself. According to Mareck-Engleke et al, ${ }^{9}$ the PD concentration may increase up to $10-100$ fold (to $10000 \mathrm{ng} / \mathrm{mL}$ ) from the baseline levels during the early pregnancy, and despite being quite theoretical in performance-sport context, the levels of $20000 \mathrm{ng} / \mathrm{mL}$ concentration can be reached just before delivery. In their recent work, Fabregat et $a l^{10}$ conducted a longitudinal study in three pregnant women, and focused on cysteine-conjugated androgens and glucuronide-conjugated androgens and oestrogens during different trimesters of pregnancy. From a steroid profile perspective, there was a significant increase in urinary oestrogen levels and moderate decrease in urinary androgen concentration, and thus alteration in general profiles due to pregnancy. Interesting results were obtained for E glucuronide concentrations, which were elevated during the first trimester, and thus a feature to take into account in interpreting of $\mathrm{T} / \mathrm{E}$ in steroid profiles of female athletes. The results of this study were also well in accordance with the earlier ones describing the formation of norandrosterone, a nandrolone metabolite, during pregnancy. ${ }^{11} 52$

\section{Metabolism, genetics and interindividual variation}

Androgens are an essential part of endocrinological homeostasis in human body and their dual effects are associated mainly to masculinisation (androgenic effects) and protein synthesis (anabolic effects). There are several mechanisms and functions which mediate the androgen action, control the transport and binding of $\mathrm{T}$ and other androgens or activate the expression of androgen-responsive genes. In human genome, two or more variants can be encountered for a particular DNA sequence. In its simplest form, this natural variation, polymorphism, involves not only a single nucleotide (SNP), but also longer DNA stretches can be involved. The outcome of the complex network of these bioprocesses and interindividual as well as interethnic variations within them leads to a steroid profile with an individual baseline of endogenous steroids. Massive amounts of research results are available on the clinical and pathological relevance of androgens and the factors contributing to the phenotype of an individual. For example, low serum T concentration is associated to several pathological conditions, for example, cardiovascular morbidity, type 2 diabetes and increased risk of mortality. As the studies indicate strong heritability of serum $\mathrm{T}$ levels and clinical studies have focused on $\mathrm{T}$ as a biomarker of male health status and on the effects of genetic variants on serum T concentrations. Although sports and doping control involve only minor fraction of population, the atypical patterns, anomalies and pathological conditions are factors to keep in mind when evaluating individual athlete profiles.

\section{Serum testosterone and physiological effects}

The earlier mentioned SHBG is the most important carrier protein for androgens. The dimeric protein consists of two identical peptide chains of 370 amino acids. SHBG synthesis is stimulated by oestrogen in the liver and decreased by androgens and anabolic steroids. Together with serum albumin (binding $40-50 \%$ of $\mathrm{T}$ ), SHBG (binding $\approx 50-60 \%$ of $\mathrm{T}$ ) forms circulating reservoir of $\mathrm{T}^{53}$ balances the concentration of free fraction and decreases the rate of metabolism in the liver. With respect to genetic variation, studies have revealed SNP which alters SHBG binding affinity for $\mathrm{T}^{54}$ Parallel to carrier proteins, there are transporter proteins which are involved in the absorption, distribution and elimination of drugs by participating to permeation of the drugs into cells and access of the drugs to their targets. ${ }^{55}$ Genetic polymorphism has also been shown to occur at this phase of bioprocesses, of which an example is the organic ion transporter OATP1B3 (encoded by SLCO1B3 gene) and its two polymorphic variants which transport $\mathrm{T}$ with varying efficiencies. ${ }^{56}$

The actions of anabolic androgenic steroids are executed via various mechanisms. At androgen receptor (AR) level, these mechanisms include indirect modulation of expression by intracellular metabolism and direct effect on the AR topology, which leads to subsequent interaction with coactivators and transcriptional activity. ${ }^{57}$ Human AR is a nuclear transcription factor, belongs to the nuclear receptor superfamily ${ }^{58}$ and mediates male sexual differentiation as well as the development and maintenance of sexual characteristics. The molecular structure of $\mathrm{AR}$ is well characterised and comprises polymorphic $\mathrm{N}$-terminal domain, a central well-conserved DNA-binding domain and a C-terminal ligand-binding domain. ${ }^{59}$ According to the literature, more than 300 mutations in the $\mathrm{X}$ linked AR gene result in androgen-insensitivity syndrome, ${ }^{60}$ and most of the mutations in the ligand-binding domain disrupt binding of the natural ligands dihydrotestosterone (DHT) and T. ${ }^{61}$

\section{Androgens metabolism}

Androgens may undergo metabolic reactions prior to their physiological effect, that is, as part of their biosynthetic pathways. As an example, enzymes CYP11A1 and CYP17 from the CYP450 family participate in the modification of cholesterol to yield $\mathrm{T}^{62}$ which is then converted to biologically more active DHT by steroid- 5 - $\alpha$-reductase type 2 enzyme (SRD5A2) in the prostate. ${ }^{63}{ }^{64}$ For rational targeting of analysis and appropriate result interpretation in doping control and for ABP purposes, however, the bioprocesses concerning metabolism and urinary excretion, and interindividual variability within these processes, are of major importance. Owing to highly non-polar nature of anabolic steroids, the parent compounds are often converted by metabolising reactions prior to their elimination and excretion in 
urine. A rough division into two main categories can be made, namely phase I and phase II metabolic reactions. These processes typically aim at termination of pharmacological activity, modification of steroid structure into less potent, more polar and better water-soluble form, and thus an enhanced excretion of steroids into urine. In human body, several organs are involved in metabolic processes, the liver being the main site of the reactions.

Phase I reactions (ie, functionalisation) of androgens include hydroxylation, oxidation and reduction, ${ }^{65}$ and involve CYP450 enzymes, dehydrogenases (eg, type $517 \beta$-hydroxysteroid dehydrogenase $\left.(\mathrm{AKR} 1 \mathrm{C} 3)^{66}\right)$ and $5 \alpha$-reductases and $5 \beta$-reductases, ${ }^{67} 68$ which catalyse the reactions. In general, CYP450 family plays a significant role in metabolism and genetic variability in humans, as $70-80 \%$ of all drugs are metabolised via isoenzymes of families CYP1, 2 and 3, and expression of each CYP is influenced by a unique combination of factors including genetic polymorphisms. From the putative 57 functional isoenzymes, the highest expressed forms in the liver are $3 \mathrm{~A} 4,2 \mathrm{C} 9,2 \mathrm{C} 8,2 \mathrm{E} 1$ and $1 \mathrm{~A} 2,{ }^{69}$ from which $3 \mathrm{~A} 4$ contributes to $6 \beta$-hydroxylation of $\mathrm{T}$ and shows ethnicityrelated polymorphism. ${ }^{70}{ }^{71}$ Furthermore, in the metabolism of T, the CYP17 gene promoter polymorphism has been suggested to explain naturally elevated $\mathrm{T} / \mathrm{E}$ ratios due to involvement in catalysis of 5 -androstene- $3 \beta, 17 \alpha$-diol, an important precursor of E. ${ }^{72}$

Phase II reactions, conjugations, play a remarkable role in the metabolism of androgens, as in an average, the unconjugated fraction represents only less than $3 \%$ of the total amount of urinary excreted compounds. ${ }^{73}$ Glucuronidation, that is, conjugation with glucuronic acid, is the main conjugation reaction of androgens in humans (figure 4A). Reaction is catalysed by UGTs, which are a family of membrane-bound enzymes in the endoplasmic reticulum. Human genome contains four UGT families, ${ }^{74}$ from which UGT1 (9 members) and UGT2 (10 members), especially the members of subfamily UGT2B, are the most significant genomes in glucuronidation of androgens. ${ }^{75-78}$ With regard to UGT isoenzymes, polymorphism has been reported for several genes, but in doping control context, a deletion polymorphism in the gene coding UGT2B17 is of profound significance. It is strongly associated with urinary levels of $\mathrm{T}$ glucuronide and thus with $\mathrm{T} / \mathrm{E}$ ratio, and interethnic variation has been observed in the prevalence of gene deletion. ${ }^{79-82}$

Sulfotransferase enzymes (SULT) transfer a sulfo moiety from a co-substrate (3'-phosphoadenosine-5'-phosphosulfate (PAPS)) to the substrate in sulfoconjugation (figure 4B). A total of 13 human cytosolic SULT genes have been identified until now, and they are categorised into families SULT1, SULT 2, SULT4 and SULT6. ${ }^{83}$ Although glucuronidation is the main conjugation pathway of endogenous androgens in humans, substrates with 3 $\beta$-hydroxy structure (eg, dehydroepiandrosterone) are sulfonated to high extent and the activity has been reported for SULT2B1, ${ }^{84}$ but especially with SULT2A1, which is polymorphic (SNPs as well as copy number variation) and for which the allelic variants are associated with decreased activity and expression. $^{8586}$

\section{Exogenous factors}

Human metabolism is subjected to significant variations caused by multiple external factors. With regard to the urinary steroid profiling, environmental conditions, drug administration and diet have been identified as sources of alteration of steroids metabolism and excretion from the body.

\section{Drugs and medication}

From the athlete and doping control perspective, all personal properties and genetic polymorphism involved at each level have an influence on the formation of 'normal profile' of an individual and justify the shift from population-based reference values to the direction of the ABP. However, the phenotype of an individual is also regulated strongly by the exogenous factors, which may temporarily interfere with the homeostasis and the metabolic routes of endogenous steroids. The effect of various pharmaceutical preparations (eg, endogenous and exogenous steroids, oral contraceptives, human chorionic gonadotropin, $\mathrm{LH}$ and glucocorticosteroids) on $\mathrm{T} / \mathrm{E}$ and steroid profile is extensively summarised earlier, especially by Mareck et $a l^{36}$ and also elsewhere, ${ }^{14}{ }^{87-91}$ emphasising the alterations in androgen synthesis arising from the feedback received via hypothalamicpituitary axis.

Another category of exogenous factors that define the steroid profile includes compounds affecting the metabolism and elimination of androgens. In general, the endogenous compounds, drugs and other xenobiotics undergo the same metabolic pathways, and thus compete and interfere (either by enzyme inhibition or induction) with each other. Taking into account the reactions connected to androgen metabolism, the most significant ones are those involving $5 \alpha$-reductases. Consequently, $5 \alpha$-reductase inhibitors, such as finasteride, which are aimed at the treatment of prostatic hyperplasia and which influence mainly the type $25 \alpha$-reductase present in prostate, suppress the
Figure 4 Schematic illustrations of (A) glucuronidation and (B) sulfoconjugation of testosterone. SULT, sulfotransferase enzymes; UGT, uridine diphosphate glucuronosyltransferase.
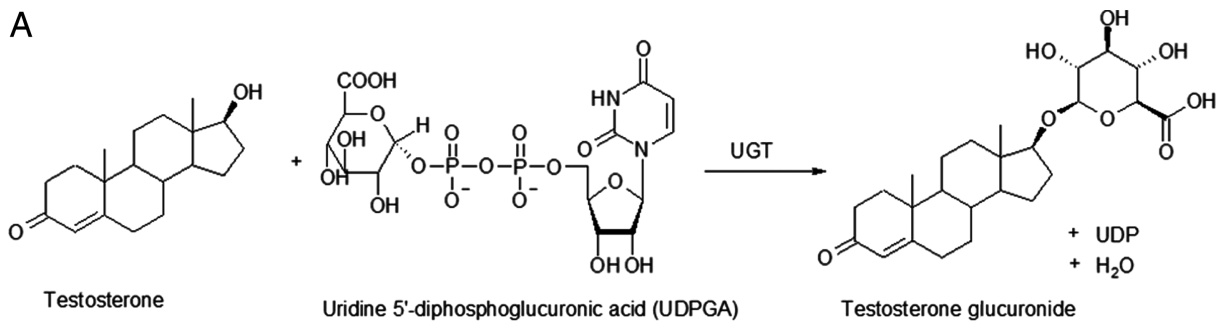

B<smiles>CC(C)(O)O[Mg]</smiles>

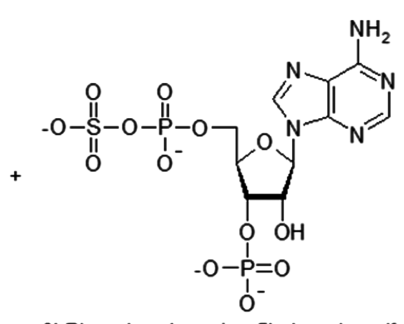

3'-Phosphoadenosine 5'-phosphosulfate (PAPS)

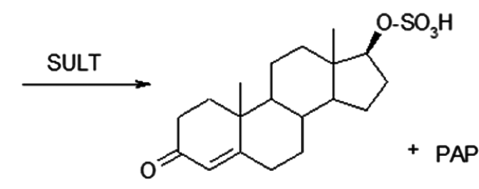

Testosterone sulfate 
formation of DHT from $\mathrm{T}^{92} 93$ and thus interfere with the interpretation of the ABP profile. Analogous to this mechanism of effects, type $517 \beta$-hydroxysteroid dehydrogenase (AKR1C3) catalyses the reduction of 4-androstene-3,17-dione to T, and the inhibition of this pathway would be desired, for example, for the treatment of hormone-dependent and hormone-independent cancers. Several compounds, such as non-steroidal antiinflammatory drugs (NSAIDs), steroid hormone analogues and benzodiazepines, have been explored as inhibitors of AKR1C $3^{66}$ and could impact the measured T concentration.

For conjugation reactions, inhibition properties of NSAIDs have been demonstrated for steroid glucuronidation in an in vitro assay, ${ }^{94}$ but the observations were not confirmed by in vivo experiments. ${ }^{95}$ One particular therapeutic drug, ketoconazole, should be mentioned due to its unique property to inhibit T synthesis, ${ }^{96} 97$ as well as the binding of DHT to SHBG, ${ }^{98}$ and to exhibit inhibition of CYP3A4 system. ${ }^{99}$ As all these features may have an implication to steroid profile, anti-doping laboratories report the presence of ketoconazole as part of confirmation analysis.

\section{Ethanol and tea}

Aside the investigated physiological effects of alcohol on physical performance skills ${ }^{100}$ and the widespread habit among top level athletes, ${ }^{101}$ ethanol could have an effect on metabolic pathways linked to steroids biotransformation, ${ }^{102-104}$ and this may be mainly due to a competitive inhibition of oxidative enzymes such as $17 \beta$-hydroxysteroid dehydrogenases (17HSD) and UGTs (ie, UGT2B17) involved in alcohol and steroid metabolisms. The main observed effects of ethanol on steroid profile are the decrease in androsterone and etiocholanolone concentrations up to $10 \%$ of the basal levels and less significant increase in $\mathrm{T}$ excretion resulting in a slight rise of $\mathrm{T} / \mathrm{E}$ ratio. ${ }^{105} 106$ Urinary steroid concentrations in women are more sensitive to these modifications caused by ethanol consumption, ${ }^{103} 107$ and obviously the dose and the frequency of alcohol abuse are key factors that determine the amplitude of alterations in metabolism.

Since quantification of urinary steroids is influenced by the presence of alcohol in the body, monitoring of alcohol markers is necessary for anti-doping laboratories. Ethylglucuronide (EtG) and ethylsulfate are widely used parameters in clinical and forensic toxicology to control ethanol consumption or abstinence. ${ }^{108-111}$ In 2011, Thieme et al ${ }^{112}$ published a study showing that EtG is the most suitable quantitative marker of ethanol consumption, allowing the evaluation of steroid profiling alteration. The question of the threshold is still remaining and various studies are in progress to establish a shared EtG concentration level at which alcohol could impact significantly the steroid concentrations.

In case of abnormally high $\mathrm{T} / \mathrm{E}$ ratio due to ethanol drinking, additional analysis with GC-C-IRMS would prove that no exogenous $\mathrm{T}$ was misused by the athlete, showing the usefulness of this technique as described further in this review. However, some precautions need to be taken in the interpretation of GC-C-IRMS results as few studies provided evidence that diet components $^{7}$ and geographical origin ${ }^{113}$ may affect delta values of the investigated steroid compounds.

Recently, Jenkinson et $a l^{114}$ reported that in vitro green and white teas suppress UGT2B17, a key enzyme for the glucuronidation of $\mathrm{T}$ (figure 4A). The inhibition of this pathway would increase free $\mathrm{T}$ level in human tissues and a potential doping in optimising free T. As for the NSAIDs, the influence of green tea on $\mathrm{T}$ metabolism, as shown in in vitro experiments, has most probably no effect on the urinary steroid profile. Furthermore, the publication of these results were appeased by anti-doping experts saying that the required amount of administered tea for a significant change in steroids concentrations is considerable and that a human interpretation of steroid profiles is always performed in any suspicious case.

\section{Environment and bacterial contamination}

Although it is known for many years that bacteria and microorganisms also alter steroid profiles, ${ }^{115}$ peer-reviewed papers investigating the ability of microbiological contamination to modify the urinary steroid profile were published only recently. ${ }^{36}$ 116-119 During the diuresis and storage in the bladder, urine is germ free, but when leaving the human body or subjected to bacterial exposure, enzyme activity linked to microorganisms may lead to a rise or a drop of endogenous steroid concentrations or even to the hydrolysis of conjugated $\mathrm{T}$ metabolites. $5 \alpha$-androstanedione and $5 \beta$-androstanedione, originating from a bacterial transformation of androsterone glucuronide and etiocholanolone glucuronide, respectively, are markers that WADA-accredited laboratories screen and quantify in urine to reveal an adulteration of the biological samples with microorganisms. ${ }^{120} 121$ Another marker of bacterial contamination is an increase of free $\mathrm{T}$ concentrations, which may lead to elevated $\mathrm{T} / \mathrm{E}$ ratio. $^{36}$

Besides modifications of endogenous steroid profiles, other anabolic androgenic steroids such as 19-nortestosterone (nandrolone) and boldenone could be produced by microorganisms in urine matrix. ${ }^{44} 118122123$ Identification of microorganisms that could be found in contaminated urine among the huge diversity of bacteria is possible through a variety of accurate methods such as sensory observations, assessing turbidity, presence of precipitate and smell and measurement of pH. In 2010, Ojanperä et al ${ }^{124}$ published an approach based on PCR and 16S rRNA gene sequencing for microbes identification, and thus potential steroid profiles adulteration.

Methods using matrix-assisted laser desorption ionisationtime of flight MS has recently been developed as a very effective tools to identify bacteria in biological fluids. ${ }^{125-127}$ This approach is of valuable interest in clinical microbiology but is not easily adapted to the prevailing technologies in the antidoping laboratories.

Despite the efficiency of these techniques, identification and quantification of microbial degradation products such as $5 \alpha$-androstanedione and $5 \beta$-androstanedione is still the preferred approach advocated by WADA in TD2014EAAS.

\section{Doping control and analytical factors}

Factors that are not dependent on technical aspects and linked to the urinary steroid profile data acquisition have been well discussed above. Nevertheless, analytical techniques that are used in WADA-accredited laboratories should also be considered when a longitudinal steroid profiles follow-up is evaluated and interpreted by anti-doping stakeholders.

\section{GC/MS versus GC-MS/MS and application of the WADA technical document}

Traditionally, anabolic androgenic steroids and their representative metabolites have been analysed by GC-MS-based methods, and the analysis of exogenous steroids has been qualitative of origin. The analysis of 'total' (ie, free and glucuronideconjugated) fraction of steroids is indirect, since glucuronideconjugated analytes are enzymatically hydrolysed before the next step of the procedure, which is typically liquid-liquid 
extraction (LLE) in alkaline environment, for example, tertbutyl methyl ether. ${ }^{36}$ For GC separation, the analytes are converted to trimethylsilyl (TMS) derivatives and in order to accomplish this effectively also to ketosteroids, the reaction mixture includes components which allow for in situ formation of trimethyl iodosilane. ${ }^{128}$ Along the developments in instrument technologies, the routine GC methods apply also tandem mass spectrometric (MS/MS) approaches to steroid analysis, which provide improved selectivity and often also higher sensitivity for the detection of analytes.

In the new situation where quantitative data are based on initial testing procedure (ITP) and are originating from different anti-doping laboratories, harmonised methodologies and uniform reporting are prerequisites for the steroid profiling. For that purpose, WADA has recently compiled a new technical document, TD2014EAAS, which is a mandatory operational procedure for laboratories to support the steroid profile quantification of the steroidal module of the ABP. ${ }^{12}$ The document gives an introduction to the steroid profiling and detailed description on the requirements for ITP and confirmation analysis.

All critical steps of the analytical procedure and monitoring of their success are covered by the document. Issues connected to sample matrix include the adjustment of the sample aliquot volume in case of diluted samples or based on the gender of the athlete with the driving force to be able to provide a reliable steroid profile for each urine sample. At later stages of the process, the laboratory should also monitor the sample integrity, for example, for the presence of microbial degradation. Most often the analytical procedure for steroid profile parameters involves hydrolysis of glucuronide-conjugated steroids, extraction of free steroids and deliberated steroid aglycons, derivatisation and GC-MS or GC-MS/MS analysis. In the method characteristics, the type of glucuronidase enzyme is specified as purified preparation for Escherichia coli to avoid by-products during the hydrolysis, the efficiency of which should also be controlled. The overall analytical process and the critical factors influencing the measurement and result interpretation of steroid profile are extensively reviewed earlier by Mareck et al, ${ }^{36}$ mentioning amineptine as an example of a drug which may inhibit $\beta$-glucuronidase activity, and, furthermore, one of its metabolites yield in MS fragmentation which may interfere the screening of androsterone and etiocholanolone. Other specific substances and factors that have been reported to affect (mainly to interfere with) the hydrolysis of steroid glucuronides, and to offer some references to the corresponding literature, include ascorbic acid, ${ }^{128}$ aspartic acid, malic acid and high concentrations of salicylic acid, ${ }^{129}$ chlorinated hydroquinones and benzoquinones, ${ }^{130}$ as well as glucosaccharic acid derivatives (eg, saccharic acid 1,4-lactone), which have been reported to inhibit $\beta$-glucuronidase activity under in vitro conditions. ${ }^{131}$

According to the technical document and GC separation, formation of TMS derivatives is required and the completeness of derivatisation step should be verified by monitoring mono-OTMS and di-O-TMS derivative of androsterone. The document sets quality requirements with respect to instrument operation and data collection by instructing the verification of the stability of calibration standards, incorporation of quality control sample with each analytical sequence and calculation of the $T / E$ ratio, as well as by setting the requirements for the sensitivity (limits of quantitation) and quantitative performance (relative standard combined uncertainty, $\mathrm{u}_{\mathrm{c}}(\%)$ ) of the method. In confirmation analysis, the analytical approach incorporates also information from GC-C-IRMS analysis (see below) and the results, quantitation and identification of the relevant steroid profile marker(s) and/or $\mathrm{T} / \mathrm{E}$ ratio.

For the result interpretation, the laboratories should also monitor the sample for the presence of $5 \alpha$-reductase inhibitors (eg, finasteride), which are not prohibited substances but may alter the steroid profile due to their mechanism of action. In confirmation analysis, the additional tests are applied to determine the presence of ethanol metabolites, ketoconazole or signs of microbial degradation, to reveal the potential external interfering factors before issuing the results into ADAMS and adaptive model purposes.

Gas chromatography-combustion-isotope ratio mass spectrometry IRMS is a powerful device that allows the source determination of the investigated compounds based on variations of stable isotopes. IRMS has many applications such as pharmacology, food research, archaeology, environment sciences and forensic science. ${ }^{132} 133$ Doping is also a domain in which IRMS can provide informative data as one of the main challenges for $\mathrm{T}$ doping detection is to establish the origin of this hormone as it could be found either produced endogenously by the body or by misuse through an exogenous administration. The first application in doping was published in 1994 by Becchi et al, ${ }^{28}$ who employed GC coupled to IRMS for the determination of carbon isotope ratio of $\mathrm{T}$ extracted from human urine. This significant work was then followed by numerous studies that explored doping detection based on the carbon isotopic ratio of endogenous hormones linked to $\mathrm{T}$ metabolism. ${ }^{7} 14$ 134-147 Recently, some $\mathrm{T}$ preparations were reported as having a similar carbon isotopic ratio compared with $\mathrm{T}$ produced endogenously, ${ }^{148} 149$ pushing scientists to find alternative methods based on hydrogen and deuterium ratio to discern naturally produced $T$ from synthetic formulations. ${ }^{150-152}$ Since its introduction in the antidoping laboratories, GC-C-IRMS has provided robust and reliable data to convict many athletes for $\mathrm{T}$ misuse in sports. Until now, GC-C-IRMS analysis was performed whenever a urine sample showed a $\mathrm{T} / \mathrm{E}$ ratio above the threshold and was considered as the ultimate proof of doping if the carbon isotopic ratio of $\mathrm{T}$ or its metabolites was significantly different from one of the defined endogenous reference compounds. ${ }^{27} \mathrm{New}$ technical document TD2014EAAS has been effective since the beginning of 2014 and according to this document, GC-C-IRMS analysis shall be applied on suspicious sample only in confirmation step after the evaluation of the steroid profile through the adaptive model of the ABP. In the case where the adaptive model cannot be used, IRMS shall be performed in specific conditions such as a $\mathrm{T} / \mathrm{E}$ ratio greater than 4 or a $\mathrm{T}$ or $\mathrm{E}$ concentration (adjusted for the specific gravity) greater than $200 \mathrm{ng} / \mathrm{mL}$ in males or greater than $50 \mathrm{ng} / \mathrm{mL}$ in females. ${ }^{12}$ More details about IRMS analyses and interpretation in WADA-accredited laboratories are expected in the upcoming new technical document dedicating to this analytical technique. In summary, GC-C-IRMS represents a complementary but necessary information source for the steroid profile evaluation.

\section{Alternative methodologies for steroid quantification}

While GC-MS (and recently GC-MS/MS) has been the analytical reference technique for steroid quantification in urine matrix for many years, some alternative approaches have been considered. First, the use of immunological tests was investigated, ${ }^{153-155}$ as the main advantages of this method is the possibility of automated processes (simple and rapid), the lower costs and the routine ease-of-use for non-scientific staff. Although ELISA assays have shown good total specificity and appropriate 
sensitivity for $\mathrm{T}$, the main drawbacks of this biochemical approach are the cross-reactivity that could lead to wrong estimation of $\mathrm{T}$ concentration and the restricted application to a single compound (eg, T) which is not compatible with the intention to establish a profile with several steroids. In addition to these limitations for steroid quantification and identification, radioimmunoassay (RIA) tests in urine present other drawbacks such as non-availability of RIA assay kits in the market for urine steroid detection and the matrix effect being more significant for RIA kits than for ELISA kits. ${ }^{156}$ Considering these disadvantages, anti-doping laboratories never deemed immunoassays as a useful tool to establish a steroid profile.

The determination of steroid concentrations by GC-MS technique requires essential steps prior to analysing the urine samples. Solid phase extraction (SPE) and/or LLE, hydrolysis, evaporation and derivatisation are necessary to obtain robust and reliable data but could also be a source of variability and inaccuracy. Measuring the steroid compounds by LC-MS instruments could overtake these steps. The first attempts were made about 30 years ago to detect steroids produced in rat liver microsomes. ${ }^{157} 158$ More recently, some authors have published LC-MS methods to quantify $\mathrm{T}$ and $\mathrm{E}$ in human urine, ${ }^{159}$ but hydrolysis and extraction steps were still required to detect the free fraction of the steroids. In the meantime, Bowers ${ }^{5}$ developed a LC-MS method for the quantification of T and E conjugates (sulfate and glucuronide) which stimulated many other authors to investigate the LC-MS detection of the steroids conjugated fraction. ${ }^{160-163}$ Whereas quantification of steroids conjugates by LC-MS was first published in 1996 by Bowers and Sanaullah, ${ }^{164}$ in 2011, Badoud et al ${ }^{165}$ presented a method based on a high-resolution MS strategy for the quantification of 11 steroids conjugates after a simple SPE step. Two years later, the same group increased the number of targeted analytes to 13 and applied their quantification method on samples collected after T administration. ${ }^{166}$ A comparison was made between data obtained with traditional GC-MS and LC-MS techniques, and as a conclusion, a good correlation was depicted showing the possibility of measuring urinary steroid based on conjugated compounds and by LC-MS technique.

Despite these promising LC-MS results, this analytical approach is not encouraged in the recently published technical document, but initial testing analysis and confirmation should be based on GC separation.

\section{CONCLUSIONS}

The establishment of urinary steroid profile through analytical quantification of $\mathrm{T}$ and its related compounds has been proven to be a reliable and efficient tool for endogenous anabolic androgenic steroids misuse detection. An additional and significant step in the steroid profile application in the fight against doping is the integration of the steroidal module within the ABP. Although the steroid profile components are quite stable against physical exercise, menstrual cycle or biological rhythms (circadian or annual), many exogenous and endogenous influencing parameters exist. These confounding factors could not be monitored only by the ABP steroidal module but need scientific expertise to be evaluated and to avoid any sanction of athlete simply based on the statistical and mechanical approach of steroid profile monitoring.

Essential part of the steroid profile is a representative number of samples, well-planned testing strategies and significant effort from sample collection authorities, as well as smooth cooperation between ADOs. Sample collection and transportation conditions should be organised in an appropriate manner to preserve the sample integrity, and the laboratories should be harmonised in analytical methodologies to provide reliable and comparable results. WADA-accredited laboratories should not only focus on endogenous steroids quantification but also on the detection of exogenous factors such as drugs interfering with metabolic pathways or adulteration markers. Genetics factors are much more sensitive considering the ethical issues.

As the final stage, the passport management units as well as the scientific expert panels should be well trained and experienced in the interpretation of analytical data and profiles in order to distinguish between ATPFs and pathological or clinical conditions which may alter the individual passport results.

In summary, a strong collaboration of every anti-doping partner, from testing strategy to result interpretation, is mandatory to optimise and to enhance the tools allowing the detection of doping with $\mathrm{T}$ and related compounds.

Summary

- New steroidal module of the athlete biological passport in place since January 2014.

- Two distinct classes of factors can influence the quantification of endogenous steroid compounds linked to testosterone and its metabolism.

- Endogenous factors include ethnicity, gender, age and genetic polymorphisms whereas exogenous factors comprise medications, diet, matrix composition and analytical tools used for the quantification.

- Implementation of the steroidal module depends on the evaluation of steroid profiles through a dedicated statistical model but also on the expertise given by specialised scientists.

\section{Competing interests None.}

Provenance and peer review Not commissioned; externally peer reviewed.

Open Access This is an Open Access article distributed in accordance with the Creative Commons Attribution Non Commercial (CC BY-NC 3.0) license, which permits others to distribute, remix, adapt, build upon this work non-commercially, and license their derivative works on different terms, provided the original work is properly cited and the use is non-commercial. See: http://creativecommons.org/ licenses/by-nc/3.0/

\section{REFERENCES}

1 Shackleton $\mathrm{CH}$. Profiling steroid hormones and urinary steroids. J Chromatogr 1986;379:91-156.

2 Radford PF. Recent developments in drug abuse and doping control in sport. $J R$ Coll Surg Edinb 1990;35:S2-6.

3 Donike M. The detection of doping by means of chromatographic methods. 1966. Drug Test Anal 2011;3:15-7.

4 Thevis M, Kuuranne T, Geyer $\mathrm{H}$, et al. Annual banned-substance review: analytical approaches in human sports drug testing. Drug Test Anal 2013;5:1-19.

5 Bowers LD. Analytical advances in detection of performance-enhancing compounds. Clin Chem 1997;43:1299-304.

6 Ojanpera I, Kolmonen M, Pelander A. Current use of high-resolution mass spectrometry in drug screening relevant to clinical and forensic toxicology and doping control. Anal Bioanal Chem 2012;403:1203-20.

7 Saudan C, Baume N, Robinson N, et al. Testosterone and doping control. Br J Sports Med 2006;40(Suppl 1):i21-4.

8 Bricout VA, Wright F, Lagoguey M. Urinary profile of androgen metabolites in a population of sportswomen during the menstrual cycle. Int J Sports Med 2003;24:197-202.

9 Mareck-Engleke U, Geyer H, Schanzer W. The interpretation of female steroid profiles. Proceedings of the 15th Manfred Donike Workshop on Dope Analysis 1997. 1998:51-70. 
10 Fabregat A, Marcos J, Garrostas L, et al. Evaluation of urinary excretion of androgens conjugated to cysteine in human pregnancy by mass spectrometry. J Steroid Biochem Mol Biol 2014;139:192-200.

11 Guay C, Goudreault D, Schanzer W, et al. Excretion of norsteroids' phase II metabolites of different origin in human. Steroids 2009;74:350-8.

12 World Anti-Doping Agency. Endogenous anabolic androgenic steroids: measurement and reporting. 2013. http://www.wada-ama.org/Documents/World Anti-Doping_Program/WADP-IS-Laboratories/Technical_Documents/WADA-TD2014 EAAS-Endogenous-Anabolic-Androgenic-Steroids-Measurement-and-Reporting-EN. pdf (accessed 16 Dec 2013).

13 Ayotte C, Goudreault D, Charlebois A. Testing for natural and synthetic anabolic agents in human urine. J Chromatogr B Biomed App/ 1996;687:3-25.

14 Ayotte $C$. Detecting the administration of endogenous anabolic androgenic steroids. Handb Exp Pharmacol 2010:(195):77-98.

15 Korenman SG, Wilson H, Lipsett MB. Isolation of 17-alpha-hydroxyandrost-4-en-3one (epitestosterone) from human urine. J Biol Chem 1964:239:1004-6.

16 Donike M, Barwald KR, Klostermann K, et al. Nachweis von exogenem testosteron [Detection of exogenous testosterone]. Sport: Leistung und Gesundheit 1983:293-8.

17 Oftebro H. Evaluating an abnormal urinary steroid profile. Lancet 1992;339:941-2.

18 Catlin DH, Hatton CK, Starcevic SH. Issues in detecting abuse of xenobiotic anabolic steroids and testosterone by analysis of athletes' urine. Clin Chem 1997:43:1280-8.

19 Sottas PE, Saudan C, Schweizer C, et al. From population- to subject-based limits of T/E ratio to detect testosterone abuse in elite sports. Forensic Sci Int 2008; $174: 166-72$

20 Robinson N, Sottas PE, Mangin P, et al. Bayesian detection of abnormal hematological values to introduce a no-start rule for heterogeneous populations of athletes. Haematologica 2007:92:1143-4.

21 Sottas PE, Robinson N, Saugy M. The athlete's biological passport and indirect markers of blood doping. Handb Exp Pharmacol 2010;(195):305-26.

22 Sottas PE, Vernec A. Current implementation and future of the Athlete Biological Passport. Bioanalysis 2012;4:1645-52.

23 Donike M. Steroid profile in cologne. Proceedings of the 10th Manfred Donike Workshop on Dope Analysis 1992. 1993:47.

24 Donike M, Mareck-Engleke U, Rauth S. Statistical evaluation of longitudinal studies, part 2: the usefulness of subject based reference ranges. In: Donike $\mathrm{M}, \mathrm{Geyer} \mathrm{H}$, Gotzmann A, Mareck-Engelke U, eds. Recent advances in doping analysis (2). Vol. 12. Köln: Sport und Buch Strauß, 1995:157-65.

25 Donike M, Rauth S, Mareck-Engelke U, et al. Evaluation of longitudinal studies, the determination of subject based reference ranges of the testosterone/ epitestosterone ratio. In: Donike M, Geyer H, Gotzmann A, Mareck-Engelke U, eds. Recent advances in doping analysis. Köln: Sport und Buch Strauß, 1994:33-40.

26 Donike M, Rauth S, Wolansky A. Reference ranges of urinary endogenous steroids determined by gas chromatography/mass spectrometry. Proceedings of the 10th Cologne Workshop on Dope Analysis 1992. 1993;Vol. 10:69-80.

27 World Anti-Doping Agency. WADA technical document-TD2004EAAS: reporting and evaluation guidance for testosterone, epitestosterone, T/E ratio and other endogenous steroids. 2004; Available from: http://www.wada-ama.org/rtecontent/ document/end_steroids_aug_04.pdf (accessed 27 Feb 2014).

28 Becchi M, Aguilera R, Farizon Y, et al. Gas chromatography/combustion/isotoperatio mass spectrometry analysis of urinary steroids to detect misuse of testosterone in sport. Rapid Commun Mass Spectrom 1994;8:304-8.

29 Sottas PE, Robinson N, Rabin 0, et al. The athlete biological passport. Clinical Chem 2011;57:969-76.

30 Sottas PE, Baume N, Saudan C, et al. Bayesian detection of abnormal values in longitudinal biomarkers with an application to T/E ratio. Biostatistics 2007:8:285-96.

31 World Anti-Doping Agency. The World Anti-Doping Code, the 2014 prohibited list international standard. 2014. http://www.wada-ama.org/Documents/World_AntiDoping_Program/WADP-Prohibited-list/2014/WADA-prohibited-list-2014-EN.pdf (accessed 27 Feb 2014).

32 Van Renterghem P, Sottas PE, Saugy M, et al. Statistical discrimination of steroid profiles in doping control with support vector machines. Anal Chim Acta 2013;768:41-8.

33 World Anti-Doping Agency. Athlete biological passport operating guidelines \& compilation of required elements. 2013. http://www.wada-ama.org/Documents/ Science_Medicine/Athlete_Biological_Passport/WADA-ABP-Operating-Guidelines_ v4.0-EN.pdf (accessed 27 Feb 2014).

34 World Anti-Doping Agency. The World Anti-Doping Code: international standard for testing. 2012. http://www.wada-ama.org/Documents/World_Anti-Doping Program/WADP-IS-Testing/2012/WADA_IST_2012_EN.pdf (accessed 27 Feb 2014).

35 van de Kerkhof DH, de Boer D, Thijssen $\mathrm{JH}$, et al. Evaluation of testosterone/ epitestosterone ratio influential factors as determined in doping analysis. J Anal Toxicol 2000;24:102-15

36 Mareck U, Geyer H, Opfermann G, et al. Factors influencing the steroid profile in doping control analysis. J Mass Spectrom 2008;43:877-91.

37 Raynaud E, Audran M, Pages JC, et al. Study of urinary excretion of testosterone and epitestosterone glucuronides in children and adolescents. Pathol Biol 1993:41:159-63.
38 Dehennin L, Delgado A, Peres G. Urinary profile of androgen metabolites at different stages of pubertal development in a population of sporting male subjects. Eur J Endocrinol 1994;130:53-9.

39 Kicman AT, Brooks RV, Collyer SC, et al. Criteria to indicate testosterone administration. Br J Sports Med 1990;24:253-64.

40 Goebel C, Howe CJ, Ho KK, et al. Screening for testosterone abuse in male athletes using the measurement of urinary $\mathrm{LH}$, a revision of the paradigm. Drug Test Anal 2009;1:511-17.

41 Schweizer C, Cardis C, Cauderay M, et al. T/E ratio variations through puberty in male adolescents. Proceedings of the 14th Manfred Donike Workshop on Dope Analysis 1996. 1997:159-71.

42 Schweizer C, Cardis C, Caudreay M, et al. Profile variations through puberty in young adolescent girls. Proceedings of the 16th Manfred Donike Workshop on Dope Analysis 1998. 1999:205-21.

43 Anderson GD. Sex differences in drug metabolism: cytochrome P-450 and uridine diphosphate glucuronosyltransferase. J Gend Specif Med 2002;5:25-33.

44 van de Kerkhof DH, van der Voort PM, de Boer D, et al. Confirmation of endogenous boldenone production: a procedure for an in vitro experiment. In: Schänzer W, Geyer H, Gotzmann A, Mareck-Engelke U, eds. Recent advances in doping analysis (7). Köln: Sport und Buch Strauß, 1999:161-7.

45 Stanton SJ, Mullette-Gillman OA, Huettel SA. Seasonal variation of salivary testosterone in men, normally cycling women, and women using hormonal contraceptives. Physiol Behav 2011;104:804-8.

46 Dabbs JM. Age and seasonal-variation in serum testosterone concentration among men. Chronobiol Int 1990:7:245-9.

47 Dabbs JM Jr. Salivary testosterone measurements: reliability across hours, days, and weeks. Physiol Behav 1990;48:83-6.

48 Mareck-Engelke U, Geyer H, Donike M. The circadian rhythm of urinary ratios and excretion rates of endogenous steroids in male. In: Recent advances in doping analysis (2). Vol. 2. Köln: Sport und Buch StrauB, 1994:121.

49 Mazzarino M, Bragano MC, de la Torre $X$, et al. Relevance of the selective oestrogen receptor modulators tamoxifen, toremifene and clomiphene in doping field: endogenous steroids urinary profile after multiple oral doses. Steroids 2011;76:1400-6.

50 Timon R, Olcina G, Maynar M, et al. Evaluation of urinary steroid profile in highly trained cyclists. J Sports Med Phys Fitness 2008:48:530-4.

51 Maynar M, Timon R, Gonzalez A, et al. SHBG, plasma, and urinary androgens in weight lifters after a strength training. J Physiol Biochem 2010;66: 137-42

52 Mareck-Engelke $U$, Schulze $G$, Geyer $H$, et al. The appearance of urinary 19-norandrosterone during pregnancy. Eur J Sport Sci 2002:2:1-7.

53 Kaufman JM, Vermeulen A. The decline of androgen levels in elderly men and its clinical and therapeutic implications. Endocr Rev 2005;26:833-76.

54 Ohlsson C, Wallaschofski H, Lunetta KL, et al. Genetic determinants of serum testosterone concentrations in men. PLoS Genet 2011;7:e1002313.

55 Russel F. Transporters: importance in drug absorption, distribution, and removal. In: Pang K, Rodrigues A, Peter R. eds. Enzyme- and transporter-based drug-drug interactions: progress and future challenges. Springer, 2010:27.

56 Sharifi N, Hamada A, Sissung $T$, et al. A polymorphism in a transporter of testosterone is a determinant of androgen independence in prostate cancer. $B J U$ Int 2008;102:617-21.

57 Kicman AT. Pharmacology of anabolic steroids. Br J Pharmacol 2008;154:502-21.

58 Mangelsdorf DJ, Thummel $C$, Beato $M$, et al. The nuclear receptor superfamily: the second decade. Cell 1995:83:835-9.

59 Ikonen T, Palvimo JJ, Janne OA. Interaction between the amino- and carboxylterminal regions of the rat androgen receptor modulates transcriptional activity and is influenced by nuclear receptor coactivators. J Biol Chem 1997;272:29821-8.

60 Gottlieb B, Beitel LK, Wu JH, et al. The androgen receptor gene mutations database (ARDB): 2004 update. Hum Mutat 2004;23:527-33.

61 Jaaskelainen J, Deeb A, Schwabe JW, et al. Human androgen receptor gene ligand-binding-domain mutations leading to disrupted interaction between the $\mathrm{N}$ and C-terminal domains. J Mol Endocrinol 2006:36:361-8.

62 Payne AH. Hormonal regulation of cytochrome P450 enzymes, cholesterol sidechain cleavage and 17 alpha-hydroxylase/C17-20 lyase in Leydig cells. Biol Reprod 1990;42:399-404.

63 Lindstrom S, Wiklund $\mathrm{F}$, Adami $\mathrm{HO}$, et al. Germ-line genetic variation in the key androgen-regulating genes androgen receptor, cytochrome P450, and steroid-5alpha-reductase type 2 is important for prostate cancer development. Cancer Res 2006:66:11077-83.

64 Schulze JJ, Thorngren JO, Garle M, et al. Androgen sulfation in healthy UDPglucuronosyl transferase 2B17 enzyme-deficient men. J Clin Endocrinol Metab 2011;96:3440-7.

65 Gibson GG, Skett P. Introduction to drug metabolism. London: Blackie Academic and Professional, Chapman\&Hall, 1994

66 Byrns MC, Jin Y, Penning TM. Inhibitors of type 5 17 $\beta$-hydroxysteroid dehydrogenase (AKR1C3): overview and structural insights. J Steroid Biochem $\mathrm{Mol}$ Biol 2011:125:95-104 
67 Jin $Y$, Mesaros AC, Blair IA, et al. Stereospecific reduction of $5 \beta$-reduced steroids by human ketosteroid reductases of the AKR (aldo-keto reductase) superfamily: role of AKR1C1-AKR1C4 in the metabolism of testosterone and progesterone via the 5 $\beta$-reductase pathway. Biochem I 2011;437:53-61.

68 Levesque $\mathrm{E}$, Laverdiere I, Lacombe L, et al. Importance of $5 \alpha$-reductase gene polymorphisms on circulating and intraprostatic androgens in prostate cancer. Clin Cancer Res 2014:20:576-84.

69 Zanger UM, Schwab M. Cytochrome P450 enzymes in drug metabolism: regulation of gene expression, enzyme activities, and impact of genetic variation. Pharmacol Ther 2013;138:103-41.

70 Shet MS, Faulkner KM, Holmans PL, et al. The effects of cytochrome b5, NADPHP450 reductase, and lipid on the rate of 6 beta-hydroxylation of testosterone as catalyzed by a human P450 3A4 fusion protein. Arch Biochem Biophys 1995:318:314-21

71 Lamba JK, Lin YS, Schuetz EG, et al. Genetic contribution to variable human CYP3A-mediated metabolism. Adv Drug Deliv Rev 2002;54:1271-94.

72 Schulze JJ, Lorentzon M, Ohlsson C, et al. Genetic aspects of epitestosterone formation and androgen disposition: influence of polymorphisms in CYP17 and UGT2B enzymes. Pharmacogenet Genomics 2008;18:477-85.

73 Dehennin L, Matsumoto AM. Long-term administration of testosterone enanthate to normal men: alterations of the urinary profile of androgen metabolites potentially useful for detection of testosterone misuse in sport. J Steroid Biochem Mol Biol 1993;44:179-89.

74 MacKenzie PI, Rogers A, Elliot DJ, et al. The novel UDP glycosyltransferase 3A2: cloning, catalytic properties, and tissue distribution. Mol Pharmacol 2011;79:472-8

75 Turgeon D, Carrier JS, Levesque $\mathrm{E}$, et al. Relative enzymatic activity, protein stability, and tissue distribution of human steroid-metabolizing UGT2B subfamily members. Endocrinology 2001;142:778-87.

76 Kuuranne T, Kurkela M, Thevis M, et al. Glucuronidation of anabolic androgenic steroids by recombinant human UDP-glucuronosyltransferases. Drug Metab Dispos 2003:31:1117-24

77 Sten T, Bichlmaier I, Kuuranne T, et al. UDP-glucuronosyltransferases (UGTs) $2 B 7$ and UGT2B17 display converse specificity in testosterone and epitestosterone glucuronidation, whereas UGT2A1 conjugates both androgens similarly. Drug Metab Dispos 2009:37:417-23.

78 Sten T, Kurkela M, Kuuranne T, et al. UDP-glucuronosyltransferases in conjugation of 5alpha- and 5beta-androstane steroids. Drug Metab Dispos 2009;37:2221-7.

79 Jakobsson J, Ekstrom L, Inotsume N, et al. Large differences in testosterone excretion in Korean and Swedish men are strongly associated with a UDP-glucuronosyl transferase 2B17 polymorphism. J Clin Endocrinol Metab 2006;91:687-93.

80 Schulze JJ, Lundmark J, Garle M, et al. Doping test results dependent on genotype of uridine diphospho-glucuronosyl transferase 2B17, the major enzyme for testosterone glucuronidation. J Clin Endocrinol Metab 2008:93:2500-6.

81 Anielski $P$, Simmchen J, Wassill $L$, et al. Epidemiological investigation of the UGT2B17 polymorphism in doping control urine samples and its correlation to T/E ratios. Drug Test Anal 2011;3:645-51.

82 Okano M, Ueda T, Nishitani Y, et al. UDP-glucuronosyltransferase 2B17 genotyping in Japanese athletes and evaluation of the current sports drug testing for detecting testosterone misuse. Drug Test Anal 2013;5:166-81.

83 Lindsay J, Wang LL, Li Y, et al. Structure, function and polymorphism of human cytosolic sulfotransferases. Curr Drug Metab 2008;9:99-105.

84 Meloche CA, Falany CN. Expression and characterization of the human 3 betahydroxysteroid sulfotransferases (SULT2B1a and SULT2B1b). I Steroid Biochem Mol Biol 2001;77:261-9.

85 Coughtrie MW. Sulfation through the looking glass-recent advances in sulfotransferase research for the curious. Pharmacogenomics J 2002;2:297-308

86 Schulze J, Johansson M, Thorngren JO, et al. SULT2A1 gene copy number variation is associated with urinary excretion rate of steroid sulfates. Front Endocrinol 2013:4:88.

87 Geyer $\mathrm{H}$, Schänzer W, Mareck-Engelke U, et al. Factors influencing the steroid profile. In: Donike M, Geyer H, Gotzmann A, Mareck-Engelke U, eds. Recent advances in doping analysis (3). Köln: Sport und Buch Strauß, 1996:95-114.

88 Van Renterghem $\mathrm{P}$, Van Eenoo $\mathrm{P}$, Geyer H, et al. Reference ranges for urinary concentrations and ratios of endogenous steroids, which can be used as markers for steroid misuse, in a Caucasian population of athletes. Steroids 2010;75:154-63.

89 Garevik N, Strahm E, Garle M, et al. Long term perturbation of endocrine parameters and cholesterol metabolism after discontinued abuse of anabolic androgenic steroids. I Steroid Biochem Mol Biol 2011;127:295-300.

90 Schonfelder M, Hofmann H, Anielski P, et al. Gene expression profiling in human whole blood samples after controlled testosterone application and exercise. Drug Test Anal 2011;3:652-60.

91 Strahm E, Marques-Vidal P, Pralong F, et al. Influence of multiple injections of human chorionic gonadotropin (hCG) on urine and serum endogenous steroids concentrations. Forensic Sci Int 2011;213:62-72.
92 Bartsch G, Rittmaster RS, Klocker H. Dihydrotestosterone and the concept of 5alpha-reductase inhibition in human benign prostatic hyperplasia. Eur Urol 2000;37:367-80.

93 Thevis M, Geyer $\mathrm{H}$, Mareck U, et al. Doping-control analysis of the 5alphareductase inhibitor finasteride: determination of its influence on urinary steroid profiles and detection of its major urinary metabolite. Ther Drug Monit 2007;29:236-47.

94 Sten T, Finel M, Ask B, et al. Non-steroidal anti-inflammatory drugs interact with testosterone glucuronidation. Steroids 2009;74:971-7.

95 Lundmark J, Garevik N, Thorngren JO, et al. Non-steroidal anti-inflammatory drugs do not influence the urinary testosterone/epitestosterone glucuronide ratio. Front Endocrinol 2013;4:51.

96 Cardis C, Schweizer C, Saugy M, et al. Ketoconazole test: blood versus urine values. In: Recent advances in doping analysis (4). Köln: Sport und Buch Strauß 1997:305-17.

97 Pont A, Williams PL, Azhar S, et al. Ketoconazole blocks testosterone synthesis. Arch Intern Med 1982;142:2137-40.

98 Grosso DS, Boyden TW, Pamenter RW, et al. Ketoconazole inhibition of testicular secretion of testosterone and displacement of steroid hormones from serum transport proteins. Antimicrob Agents Chemother 1983;23:207-12.

99 Gibbs MA, Thummel KE, Shen DD, et al. Inhibition of cytochrome P-450 3A (CYP3A) in human intestinal and liver microsomes: comparison of Ki values and impact of CYP3A5 expression. Drug Metab Dispos 1999;27:180-7.

100 Pesta DH, Angadi SS, Burtscher M, et al. The effects of caffeine, nicotine, ethanol, and tetrahydrocannabinol on exercise performance. Nutr Metab 2013;10:71.

101 O'Brien CP, Lyons F. Alcohol and the athlete. Sports Med 2000;29:295-300.

102 Falk $\mathrm{O}$, Palonek E, Bjorkhem I. Effect of ethanol on the ratio between testosterone and epitestosterone in urine. Clin Chem 1988;34:1462-4.

103 Karila T, Kosunen V, Leinonen A, et al. High doses of alcohol increase urinary testosterone-to-epitestosterone ratio in females. J Chromatogr B Biomed Appl 1996;687:109-16.

104 Sarkola T, Eriksson CJ. Testosterone increases in men after a low dose of alcohol. Alcohol Clin Exp Res 2003;27:682-5.

105 Geyer H, Mareck U, Haenelt N, et al. Atypical steroid profiles in connection with ethanol findings in urine. Proceedings of the 27th Manfred Donike Workshop on Dope Analysis 2009. 2009;27:261-4

106 Grosse J, Anielski P, Sachs H, et al. Ethylglucuronide as a potential marker for alcohol-induced elevation of urinary testosterone/epitestosterone ratios. Drug Test Anal 2009:1:526-30.

107 Seppenwoolde-Waasdorp TJA, de Boer D, van Engelen HMJ, et al. Evaluation of endogenous steroid profiles in urine (2). Effects of ethanol intake reinvestigated.Â. Proceedings of the 13th Manfred Donike Workshop on Dope Analysis 1995. 1996;2:157-65.

108 Weinmann W, Schaefer $P$, Thierauf A, et al. Confirmatory analysis of ethylglucuronide in urine by liquid-chromatography/electrospray ionization/tandem mass spectrometry according to forensic guidelines. J Am Soc Mass Spectrom 2004;15:188-93.

109 Wurst FM, Dresen S, Allen JP, et al. Ethyl sulphate: a direct ethanol metabolite reflecting recent alcohol consumption. Addiction 2006;101:204-11.

110 Kissack JC, Bishop J, Roper AL. Ethylglucuronide as a biomarker for ethanol detection. Pharmacotherapy 2008;28:769-81.

111 Halter CC, Laengin A, Al-Ahmad A, et al. Assessment of the stability of the ethanol metabolite ethyl sulfate in standardised degradation tests. Forensic Sci Int 2009:186:52-5

112 Thieme D, Grosse J, Keller L, et al. Urinary concentrations of ethyl glucuronide and ethyl sulfate as thresholds to determine potential ethanol-induced alteration of steroid profiles. Drug Test Anal 2011;3:851-6.

113 Strahm E, Emery C, Saugy M, et al. Detection of testosterone administration based on the carbon isotope ratio profiling of endogenous steroids: international reference populations of professional soccer players. Br I Sports Med 2009:43:1041-4.

114 Jenkinson C, Petroczi A, Naughton DP. Red wine and component flavonoids inhibit UGT2B17 in vitro. Nutr J 2012;11:67.

115 Talalay P. Enzymatic mechanisms in steroid metabolism. Physiol Rev 1957;37:362-89.

116 de la Torre R, de la Torre X, Alia C, et al. Changes in androgenic steroid profile due to urine contamination by microorganisms: a prospective study in the context of doping control. Anal Biochem 2001;289:116-23.

117 Kicman AT, Fallon JK, Cowan DA, et al. Candida albicans in urine can produce testosterone: impact on the testosterone/epitestosterone sports drug test. Clin Chem 2002;48:1799-801.

118 Hebestreit M, Flenker U, Fussholler $\mathrm{G}$, et al. Determination of the origin of urinary norandrosterone traces by gas chromatography combustion isotope ratio mass spectrometry. Analyst 2006;131:1021-6.

119 Van Eenoo P, Lootens L, Spaerkeer A, et al. Results of stability studies with doping agents in urine. J Anal Toxicol 2007:31:543-8. 
120 Ayotte C, Charlebois A, Lapointe D, et al. Validity of urine samples: microbial degradation. In: Donike M, Geyer H, Gotzmann A, Mareck-Engelke U, eds. Recent advances in doping analysis (4). Köln: Sport und Buch Strauß, 1997:127-37.

121 Mazzarino M, Abate MG, Alocci R, et al. Urine stability and steroid profile: towards a screening index of urine sample degradation for anti-doping purpose. Anal Chim Acta 2011;683:221-6.

122 Grosse J, Anielski P, Hemmersbach P, et al. Formation of 19-norsteroids by in situ demethylation of endogenous steroids in stored urine samples. Steroids 2005;70:499-506

123 Leinonen A, Apajalahti J, Moisander T, et al. Experiments on production of 'endogenous boldenone'.Â. Proceedings of the 25th Manfred Donike Workshop on Dope Analysis 2007. 2007:163-8.

124 Ojanperä S, Leinonen A, Apajalahti J, et al. Characterization of microbial contaminants in urine. Drug Test Anal 2010;2:576-81.

125 Ferreira L, Sanchez-Juanes F, Gonzalez-Avila M, et al. Direct identification of urinary tract pathogens from urine samples by matrix-assisted laser desorption ionization-time of flight mass spectrometry. J Clin Microbio 2010;48:2110-15

126 Seng P, Rolain JM, Fournier PE, et al. MALDI-TOF-mass spectrometry applications in clinical microbiology. Future Microbiol 2010;5:1733-54.

127 March Rossello GA, Gutierrez Rodriguez MP, de Lejarazu Leonardo RO, et al. Procedure for microbial identification based on matrix-assisted laser desorption/ ionization-time of flight mass spectrometry from screening-positive urine samples. APMIS 2013. doi:10.1111/apm.12208

128 Young JC, Kenyon EM, Calabrese EJ. Inhibition of beta-glucuronidase in human urine by ascorbic acid. Hum Exp Toxicol 1990;9:165-70.

129 Mazzarino M, Botre F. How safe are our internal procedures? Some preliminary experimental evidence on the problem of 'lab-oriented' potential masking agents. Proceedings of the 25th Manfred Donike Workshop on Dope Analysis 2007. 2007:25:49-58.

130 Ahlborg UG, Manzoor E, Thunberg T. Inhibition of beta-glucuronidase by chlorinated hydroquinones and benzoquinones. Arch Toxicol 1977;37:81-7.

131 Oleson L, Court MH. Effect of the beta-glucuronidase inhibitor saccharolactone on glucuronidation by human tissue microsomes and recombinant UDP-glucuronosyltransferases. J Pharm Pharmacol 2008;60:1175-82.

132 Benson S, Lennard C, Maynard P, et al. Forensic applications of isotope ratio mass spectrometry—a review. Forensic Sci Int 2006;157:1-22.

133 Flenker U. Isotope ratio mass spectrometry - history and terminology in brief. Drug Test Anal 2012:4:893-6.

134 Aguilera R, Becchi M, Casabianca $\mathrm{H}$, et al. Improved method of detection of testosterone abuse by gas chromatography/combustion/isotope ratio mass spectrometry analysis of urinary steroids. J Mass Spectrom 1996;31:169-76.

135 Aguilera R, Becchi M, Grenot C, et al. Detection of testosterone misuse: comparison of two chromatographic sample preparation methods for gas chromatographic-combustion/isotope ratio mass spectrometric analysis. J Chromatogr B Biomed App/ 1996;687:43-53.

136 Shackleton $\mathrm{CH}$, Phillips $\mathrm{A}$, Chang $\mathrm{T}$, et al. Confirming testosterone administration by isotope ratio mass spectrometric analysis of urinary androstanediols. Steroids 1997:62:379-87.

137 Aguilera R, Catlin DH, Becchi M, et al. Screening urine for exogenous testosterone by isotope ratio mass spectrometric analysis of one pregnanediol and two androstanediols. J Chromatogr B Biomed Sci Appl 1999;727:95-105.

138 Aguilera R, Chapman TE, Starcevic B, et al. Performance characteristics of a carbon isotope ratio method for detecting doping with testosterone based on urine diols: controls and athletes with elevated testosterone/epitestosterone ratios. Clin Chem 2001:47:292-300.

139 Saudan C, Baume N, Mangin P, et al. Urinary analysis of 16(5alpha)-androsten3alpha-ol by gas chromatography/combustion/isotope ratio mass spectrometry: implications in anti-doping analysis. J Chromatogr B Analyt Technol Biomed Life Sci 2004;810:157-64.

140 Saudan C, Kamber M, Barbati G, et al. Longitudinal profiling of urinary steroids by gas chromatography/combustion/isotope ratio mass spectrometry: diet change may result in carbon isotopic variations. J Chromatogr B Analyt Technol Biomed Life Sci 2006;831:324-7.

141 Cawley AT, Flenker U. The application of carbon isotope ratio mass spectrometry to doping control. J Mass Spectrom 2008;43:854-64.

142 Flenker U, Guntner U, Schanzer W. delta13C-values of endogenous urinary steroids. Steroids 2008;73:408-16.
143 Piper T, Mareck U, Geyer $\mathrm{H}$, et al. Determination of $13 \mathrm{C} / 12 \mathrm{C}$ ratios of endogenous urinary steroids: method validation, reference population and application to doping control purposes. Rapid Commun Mass Spectrom 2008;22:2161-75.

144 Saudan C, Emery C, Marclay F, et al. Validation and performance comparison of two carbon isotope ratio methods to control the misuse of androgens in humans. J Chromatogr B Analyt Technol Biomed Life Sci 2009;877:2321-9.

145 Mareck U, Geyer H, Fussholler G, et al. Reporting and managing elevated testosterone/epitestosterone ratios - novel aspects after five years' experience. Drug Test Anal 2010;2:637-42.

146 Van Renterghem $\mathrm{P}$, Polet M, Brooker $\mathrm{L}$, et al. Development of a GC/C/IRMS method-confirmation of a novel steroid profiling approach in doping control. Steroids 2012;77:1050-60.

147 Baume N, Saudan C, Desmarchelier A, et al. Use of isotope ratio mass spectrometry to detect doping with oral testosterone undecanoate: inter-individual variability of $13 \mathrm{C} / 12 \mathrm{C}$ ratio. Steroids 2006;71:364-70.

148 Cawley A, Collins M, Kazlauskas $R$, et al. Stable isotope ratio profiling of testosterone preparations. Drug Test Anal 2010;2:557-67.

149 Forsdahl G, Ostreicher C, Koller M, et al. Carbon isotope ratio determination and investigation of seized testosterone preparations. Drug Test Anal 2011;3:814-19.

150 Piper T, Thevis M, Flenker $\mathrm{U}$, et al. Determination of the deuterium/hydrogen ratio of endogenous urinary steroids for doping control purposes. Rapid Commun Mass Spectrom 2009;23:1917-26.

151 Piper $T$, Thomas $A$, Thevis $M$, et al. Investigations on hydrogen isotope ratios of endogenous urinary steroids: reference-population-based thresholds and proof-of-concept. Drug Test Anal 2012;4:717-27.

152 Piper T, Emery C, Thomas A, et al. Combination of carbon isotope ratio with hydrogen isotope ratio determinations in sports drug testing. Anal Bioanal Chem 2013;405:5455-66.

153 Al-Dujaili EA. Development and validation of a simple and direct ELISA method for the determination of conjugated (glucuronide) and non-conjugated testosterone excretion in urine. Clin Chim Acta 2006;364:172-9.

154 Cadwallader AB, Lim CS, Rollins DE, et al. The androgen receptor and its use in biological assays: looking toward effect-based testing and its applications. J Anal Toxicol 2011:35:594-607.

155 Tort N, Salvador JP, Marco MP. Multiplexed immunoassay to detect anabolic androgenic steroids in human serum. Anal Bioanal Chem 2012;403:1361-71.

156 Venturelli $E$, Cavalleri A, Secreto $G$. Methods for urinary testosterone analysis. J Chromatogr B Biomed Appl 1995;671:363-80.

157 Wood AW, Ryan DE, Thomas PE, et al. Regio- and stereoselective metabolism of two $\mathrm{C} 19$ steroids by five highly purified and reconstituted rat hepatic cytochrome P-450 isozymes. J Biol Chem 1983;258:8839-47.

158 Sonderfan AJ, Arlotto MP, Dutton DR, et al. Regulation of testosterone hydroxylation by rat liver microsomal cytochrome P-450. Arch Biochem Biophys 1987;255:27-41.

159 Navajas R, Imaz C, Carreras D, et al. Determination of epitestosterone and testosterone in urine by high-performance liquid chromatography. J Chromatogr $B$ Biomed App/ 1995;673:159-64.

160 Bean KA, Henion JD. Direct determination of anabolic steroid conjugates in human urine by combined high-performance liquid chromatography and tandem mass spectrometry. J Chromatogr B Biomed Sci Appl 1997;690:65-75.

161 Antignac JP, Brosseaud A, Gaudin-Hirret I, et al. Analytical strategies for the direct mass spectrometric analysis of steroid and corticosteroid phase II metabolites. Steroids 2005;70:205-16.

162 Pozo OJ, Van Eenoo P, Van Thuyne W, et al. Direct quantification of steroid glucuronides in human urine by liquid chromatography-electrospray tandem mass spectrometry. J Chromatogr A 2008;1183:108-18.

163 Strahm E, Kohler I, Rudaz S, et al. Isolation and quantification by high-performance liquid chromatography-ion-trap mass spectrometry of androgen sulfoconjugates in human urine. J Chromatogr A 2008;1196-1197:153-60.

164 Bowers LD, Sanaullah. Direct measurement of steroid sulfate and glucuronide conjugates with high-performance liquid chromatography-mass spectrometry. J Chromatogr B Biomed Appl 1996;687:61-8.

165 Badoud F, Grata E, Boccard J, et al. Quantification of glucuronidated and sulfated steroids in human urine by ultra-high pressure liquid chromatography quadrupole time-of-flight mass spectrometry. Anal Bioanal Chem 2011;400:503-16.

166 Badoud F, Boccard J, Schweizer C, et al. Profiling of steroid metabolites after transdermal and oral administration of testosterone by ultra-high pressure liquid chromatography coupled to quadrupole time-of-flight mass spectrometry. J Steroid Biochem Mol Biol 2013;138:222-35. 